\title{
PET/CT imaging and the oligometastatic prostate cancer patient: an opportunity for a curative approach with high-dose radiotherapy?
}

\author{
Raymond Miralbell • Franz Buchegger
}

Published online: 13 May 2014

(C) Springer-Verlag Berlin Heidelberg 2014

\begin{abstract}
Although not curative, androgen deprivation (AD) therapy is presently the first treatment option for patients with recurrent and/or metastatic prostate cancer [1]. Metastatic prostate cancer most frequently becomes resistant to continuous $\mathrm{AD}$ after an average treatment time of $2-3$ years [2]. Furthermore, long-term $\mathrm{AD}$ may induce substantial side effects in patients compromising general health status and quality of life including cognitive and sexual impairment, fatigue, cardiovascular dysfunction, metabolic syndrome, loss of lean body mass, and osteoporosis [3-5]. Intermittent short courses of AD have been proposed as an alternative to continuous $\mathrm{AD}$ and tested in several phase II/III trials with the aim of reducing the severity and duration of the above-mentioned side effects and of delaying further the clinical appearance and progression of hormone-independent disease [6, 7]. However, these trials have been unable to show a survival benefit of intermittent compared to continuous AD. Nevertheless, substrata analysis from a pre-PET/CT era randomized trial (RTOG 8531) that recruited patients between 1987 and 1992 and compared continuous $\mathrm{AD}$ plus radiation with radiation alone in patients with pathological node-positive adenocarcinoma of the prostate showed 5-year biochemical control (i.e. PSA $<1.5 \mathrm{ng} / \mathrm{ml}$ ) in $54 \%$ of the combined treatment arm versus $33 \%$ of the radiation-only arm [8]. The 9-year absolute survival rate was $62 \%$ in patients treated with combined treatment [8]. In other words, patients with disease in the
\end{abstract}

\footnotetext{
R. Miralbell $(\bowtie)$

Radiation Oncology Division, University Hospital of Geneva-CH, Genève, Switzerland

e-mail: RAYMOND.MIRALBELL@HCUGE.CH

R. Miralbell

Institut Oncològic Teknon, Barcelona, Spain

F. Buchegger

Nuclear Medicine Division, University Hospital of Lausanne-CH, Lausanne, Switzerland
}

pelvic or paraaortic lymph node regions treated with a combination of $\mathrm{AD}$ and curative intent radiotherapy can expect long-term survival despite their metastatic status.

A large majority of patients with early biochemical failure after treatment of their primary tumour with curative intent have no evidence of disease on standard imaging such as bone scan or abdominal CT unless the PSA increases above $20 \mathrm{ng} / \mathrm{ml}$ [9]. PET/CT tracers for prostate cancer, including ${ }^{11} \mathrm{C}$-acetate, ${ }^{11} \mathrm{C}$-choline and ${ }^{18} \mathrm{~F}$-choline, were developed more than a decade ago and their role as reliable imaging tools for assessing the extension of disease in patients with biochemical failure in an earlier stage has slowly widened [10, 11]. Head-to-head comparisons of these three different tracers are relatively scarce and frequently include only small numbers of patients. We have recently shown with PET/CT that ${ }^{11} \mathrm{C}$-acetate and ${ }^{18} \mathrm{~F}$-choline produce very similar imaging results in patients with early relapse of prostate cancer [12]. The relapse status of local, regional and distant sites can be properly assessed with these imaging techniques so that the salvage treatment approach can be optimized.

An oligometastatic status is not an uncommon clinical situation in patients with disseminated prostate cancer. Indeed, Harada et al. observed a large proportion of patients with one or two metastases in an autopsy series of 136 patients: $36 \%$ and $32 \%$ of patients had one and two bone lesions, respectively [13] . Only $10 \%$ of patients had four or more bone metastases. As mentioned above, it has been suggested that the number of metastatic lesions in prostate cancer patients may be an important prognosticator. Singh et al. reported that patients with up to five metastases had a 5-year overall survival similar to metastases-free patients and significantly better than patients with more than five metastases ( $73 \%$ versus $45 \%$ ) [14]. The authors concluded that oligometastatic patients may harbour tumours biologically less aggressive with limited metastatic potential and a slow growth rate. These patients may be suitable for more aggressive treatment approaches. 
Although PET/CT imaging techniques with choline or acetate tracers are diagnostic procedures with a potentially higher predictive value than $\mathrm{CT}$ and bone scans, their predictive value in patients with low PSA levels (i.e. early relapse scenario) is low. Indeed, during early progression PSA may most frequently be below $4 \mathrm{ng} / \mathrm{ml}$ if the failure follows radiotherapy or far below $1 \mathrm{ng} / \mathrm{ml}$ if the failure is detected after radical prostatectomy. Such a low PSA level is limiting factor for the detection of the suspected relapse site(s) even with choline or acetate tracers. In a recent study in 156 patients with recurrent prostate cancer after surgery or radiotherapy, PSA levels tended to be significantly lower in patients with a negative PET/CT choline study (median PSA $1.2 \mathrm{ng} / \mathrm{ml}$, range $0.1-30.3 \mathrm{ng} / \mathrm{ml}$ ) than in those with a positive scan (median PSA $4.5 \mathrm{ng} / \mathrm{ml}$, range $0.15-296.61 \mathrm{ng} / \mathrm{ml}$ ) [15]. Scattoni et al. found a relatively low sensitivity of $64 \%$ for nodal metastases with ${ }^{11} \mathrm{C}$-choline $\mathrm{PET} / \mathrm{CT}$ imaging in patients with biochemical progression after prostatectomy [16]. Delayed scanning with three-phase ${ }^{18} \mathrm{~F}$ choline PET/CT may improve the positive predictive value of this investigation by better discriminating benign from suspicious inflammatory lymph nodes [17].

Several authors have tried to use the tracing potential of choline and/or acetate PET/CT studies to develop potentially curative treatment strategies for patients with a limited number of metastases. The use of surgery (targeted lymph node resection) or high-dose targeted radiotherapy most frequently combined with $\mathrm{AD}$ has been described $[18,19]$. In the present issue of EJNMMI, Picchio et al. report on the potential value of PET/CT choline studies for optimizing treatment with highdose radiation beams of patients with metastatic lymph nodes at relapse. In 42 of 47 patients (90\%) assessed with a PET/CT examination after salvage irradiation they observed a complete or partial metabolic response [20]. Considering the limited sensitivity of PET/CT choline studies, as mentioned above, most of their patients were treated when feasible with extended fields including the entire pelvic or paraaortic lymph node region in the vicinity of the lymph nodes positive on $\mathrm{PET} / \mathrm{CT}$, the latter receiving an additional boost dose [20].

Nonetheless, despite the good local response rates after high-dose radiation or salvage lymph-node excision the reported 3-year biochemical progression-free survival figures are relatively modest $(<30-40 \%)[18,19]$. Only patients with a limited number of metastases on PET/CT with choline or acetate at first treatment or at relapse might be candidates for an aggressive treatment strategy that combines limited duration $\mathrm{AD}(9-12$ months) with high-dose radiation ( $>64 \mathrm{~Gy})$ to the tracer positive metastatic lesions. Indeed, we have recently reported on the treatment of patients with oligometastatic prostate cancer (up to four sites) combining $\mathrm{AD}$ (median duration 12 months) with high-dose focused radiation to the metastatic sites (lymph node and/or distant sites) detected with choline or acetate PET/CT [21]. The 3-year biochemical-free survival $(\mathrm{PSA}<1 \mathrm{ng} / \mathrm{ml}$ ) and clinical failure-free survival in the 50 oligometastatic patients in this study were $54.5 \%$ and $58.6 \%$, respectively. Furthermore, patients receiving a normalized total dose of $>64$ Gy showed a significantly better biochemical-free survival ( $65 \%$ vs. $41.8 \%$ for those receiving $\leq 64 \mathrm{~Gy}$ ) in the multivariate analysis [21].

While the widely used choline tracers for prostate cancer show good detection rates notably for local recurrences, they appear less specific for lymph node and bone metastases. Indeed, several groups have expressed doubts about the detection of positive lymph node and bone metastases with choline tracers probably because of potential uptake artefacts caused by inflammatory reactions and degenerative bone disease, respectively. Research, notably at the preclinical level, on new radiopharmaceuticals for the detection of prostate cancer has been ongoing in recent years. Recently, the first promising clinical results with bombesin [22-24] and PSMA ligand [25-27] analogues have been reported. These two tracers are among the top currently investigated tracers that recognize gastrin-releasing peptides (GRP) and the PSMA receptors identified in large amount and in a high percentage of prostate cancers. The PSMA ligand MIP-1095 radiolabelled with ${ }^{131} \mathrm{I}$ has already been used therapeutically, and represents a new potential approach to the treatment of disseminated prostate cancer [27].

In summary, despite limited sensitivity and specificity for acetate and choline tracers, patients with oligometastatic prostate cancer may benefit from targeted high-dose irradiation of the suspected lesions associated with a short course of AD. This hypothesis needs to be confirmed in a phase III trial comparing intermittent $\mathrm{AD}$ with or without a complement of targeted irradiation. Optimizing the local tumoricidal effect of radiotherapy against gross disease will certainly not cure patients with oligometastatic cancer but may prolong the biochemical and clinical disease-free interval between $\mathrm{AD}$ cycles, thus improving the limited efficacy of $\mathrm{AD}$ with good quality overall survival. New upcoming tracers such as those recognizing GRP and PSMA receptors may help in the future to better assess the extension status of primary or recurrent disease and to better tailor adapted strategies aiming to optimize the potentially curative treatment of patients with oligometastatic prostate cancer.

\section{References}

1. Loblaw DA, Virgo KS, Nam R, Somerfield MR, Ben-josef E, Mendelson DS, et al. Initial hormonal management of androgensensitive metastatic, recurrent, or progressive prostate cancer: 2006 update of an American Society of Clinical Oncology practice guideline. J Clin Oncol. 2007;25:1596-605.

2. Eisenberger MA, Blumenstein BA, Crawford ED, Miller G, Mcleod DG, Loehrer PJ, et al. Bilateral orchiectomy with or without flutamide for metastatic prostate cancer. N Engl J Med. 1998;339: $1036-42$. 
3. Alibhai SM, Gogov S, Allibhai Z. Long-term side effects of androgen deprivation therapy in men with non-metastatic prostate cancer: a systematic literature review. Crit Rev Oncol Hematol. 2006;60:20115 .

4. Sadetsky N, Lubeck DP, Pasta DJ, Latini DM, Duchane J, Carroll PR. Insurance and quality of life in men with prostate cancer: data from the Cancer of the Prostate Strategic Urological Research Endeavor. BJU Int. 2008;101:691-7.

5. Kyrdalen AE, Dahl AA, Hernes E, Hem E, Fossa SD. Fatigue in prostate cancer survivors treated with definitive radiotherapy and LHRH analogs. Prostate. 2010;70:1480-9.

6. Da Calais Silva FE, Bono AV, Whelan P, Brausi M, Marques Queimadelos A, Martin JA, et al. Intermittent androgen deprivation for locally advanced and metastatic prostate cancer: results from a randomised phase 3 study of the South European Uroncological Group. Eur Urol. 2009;55:1269-77.

7. Crook JM, O'Callaghan CJ, Duncan G, Dearnaley DP, Higano CS, Horwitz EM, et al. Intermittent androgen suppression for rising PSA level after radiotherapy. N Engl J Med. 2012;367:895-903.

8. Lawton CA, Winter K, Grignon D, Pilepich MV. Androgen suppression plus radiation versus radiation alone for patients with stage D1/ pathologic node-positive adenocarcinoma of the prostate: updated results based on national prospective randomized trial Radiation Therapy Oncology Group 85-31. J Clin Oncol. 2005;23:800-7.

9. Mottet N, Bellmunt J, Bolla M, Joniau S, Mason M, Matveev V, et al. EAU guidelines on prostate cancer. Part II: Treatment of advanced, relapsing, and castration-resistant prostate cancer. Eur Urol. 2011;59: 572-83.

10. Brogsitter C, Zophel K, Kotzerke J. 18F-Choline, 11C-choline and $11 \mathrm{C}$-acetate $\mathrm{PET} / \mathrm{CT}$ : comparative analysis for imaging prostate cancer patients. Eur J Nucl Med Mol Imaging. 2013;40 Suppl 1:S18-27.

11. Picchio M, Giovannini E, Messa C. The role of PET/computed tomography scan in the management of prostate cancer. Curr Opin Urol. 2011;21:230-6.

12. Buchegger F, Garibotto V, Zilli T, Allainmat L, Jorcano S, Vees H, et al. First imaging results of an intraindividual comparison of (11)Cacetate and (18)F-fluorocholine PET/CT in patients with prostate cancer at early biochemical first or second relapse after prostatectomy or radiotherapy. Eur J Nucl Med Mol Imaging. 2014;41:68-78.

13. Harada M, Iida M, Yamaguchi M, Shida K. Analysis of bone metastasis of prostatic adenocarcinoma in 137 autopsy cases. Adv Exp Med Biol. 1992;324:173-82.

14. Singh D, Yi WS, Brasacchio RA, Muhs AG, Smudzin T, Williams JP, et al. Is there a favorable subset of patients with prostate cancer who develop oligometastases? Int J Radiat Oncol, Biol, Phys. 2004;58:3-10.

15. Soyka JD, Muster MA, Schmid DT, Seifert B, Schick U, Miralbell R, et al. Clinical impact of $18 \mathrm{~F}$-choline PET/CT in patients with recurrent prostate cancer. Eur J Nucl Med Mol Imaging. 2012;39(6):936-43.

16. Scattoni V, Picchio M, Suardi N, Messa C, Freschi M, Roscigno M, et al. Detection of lymph-node metastases with integrated
$[11 \mathrm{C}]$ choline PET/CT in patients with PSA failure after radical retropubic prostatectomy: results confirmed by open pelvicretroperitoneal lymphadenectomy. Eur Urol. 2007;52:423-9.

17. Steiner C, Vees H, Zaidi H, Wissmeyer M, Berrebi O, Kossovsky $\mathrm{MP}$, et al. Three-phase 18F-fluorocholine PET/CT in the evaluation of prostate cancer recurrence. Nuklearmedizin. 2009;48:1-9.

18. Rigatti P, Suardi N, Briganti A, Da Pozzo LF, Tutolo M, Villa L, et al. Pelvic/retroperitoneal salvage lymph node dissection for patients treated with radical prostatectomy with biochemical recurrence and nodal recurrence detected by (11C)choline positron emission tomography/computed tomography. Eur Urol. 2011;60:935-43.

19. Würschmidt F, Petersen C, Wahl A, Dahle J, Kretschmer M. $[18 \mathrm{~F}]$ fluoroethylcholine-PET/CT imaging for radiation treatment planning of recurrent and primary prostate cancer with dose escalation to PET/CT-positive lymph nodes. Radiat Oncol. 2011;6:44

20. Picchio M, Berardi G, Fodor A, Busnardo E, Crivellaro C, Giovacchini $\mathrm{G}$, et al. 11C-Choline PET/CT as a guide to radiation treatment planning of lymph-node relapses in prostate cancer patients. Eur J Nucl Med Mol Imaging. 2014. doi:10.1007/S00259014-2734-6.

21. Schick U, Jorcano S, Nouet P, Rouzaud M, Vees H, Zilli T, et al. Androgen deprivation and high-dose radiotherapy for oligometastatic prostate cancer patients with less than five regional and/or distant metastases. Acta Oncol. 2013;52:1622-8.

22. Kahkonen E, Jambor I, Kemppainen J, Lehtio K, Gronroos TJ, Kuisma A, et al. In vivo imaging of prostate cancer using [68Ga]labeled bombesin analog BAY86-7548. Clin Cancer Res. 2013;19: $5434-43$

23. Roivainen A, Kahkonen E, Luoto P, Borkowski S, Hofmann B, Jambor I, et al. Plasma pharmacokinetics, whole-body distribution, metabolism, and radiation dosimetry of $68 \mathrm{Ga}$ bombesin antagonist BAY 86-7548 in healthy men. J Nucl Med. 2013;54:867-72.

24. Wieser G, Mansi R, Grosu AL, Schultze-Seemann W, DumontWalter RA, Meyer PT, et al. Positron emission tomography (PET) imaging of prostate cancer with a gastrin releasing peptide receptor antagonist - from mice to men. Theranostics. 2014;4:412-9.

25. Afshar-Oromieh A, Zechmann CM, Malcher A, Eder M, Eisenhut M, Linhart HG, et al. Comparison of PET imaging with a (68)Galabelled PSMA ligand and (18)F-choline-based PET/CT for the diagnosis of recurrent prostate cancer. Eur J Nucl Med Mol Imaging. 2014;41:11-20.

26. Afshar-Oromieh A, Haberkorn U, Schlemmer HP, Fenchel M, Eder $\mathrm{M}$, Eisenhut M, et al. Comparison of PET/CT and PET/MRI hybrid systems using a (68)Ga-labelled PSMA ligand for the diagnosis of recurrent prostate cancer: initial experience. Eur J Nucl Med Mol Imaging. 2014;41:887-97.

27. Zechmann CM, Afshar-Oromieh A, Armor T, Stubbs JB, Mier W, Hadaschik B, et al. Radiation dosimetry and first therapy results with a 124I/131I-labeled small molecule (MIP-1095) targeting PSMA for prostate cancer therapy. Eur J Nucl Med Mol Imaging. 2014. doi:10. 1007/S00259-014-2713-y. 